\title{
La construcción mediática de las crisis políticas
}

\author{
Pablo Lopez-Rabadan*
}

CASERO RIPOLLÉS, Andreu. La construcción mediática de las crisis políticas. Madri: Fragua, 2009. 342p.

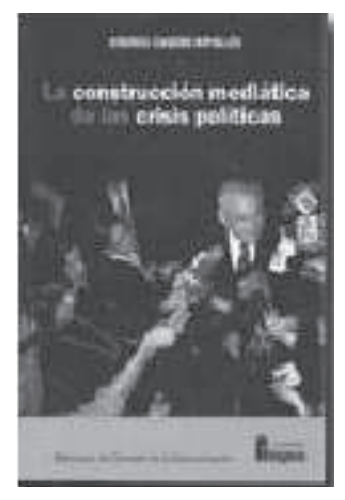

$\mathrm{T}$ al como indica su título, este libro se adentra en uno de los grandes temas de la investigación comunicativa actual, la construcción mediática de la realidad social. Y lo hace apostando por la recuperación de sus fuentes teóricas originales y una clara proyección empírica dentro de los estudios de comunicación política.

Actualmente, se reconoce de forma generalizada la centralidad de los medios de comunicación en las dinámicas sociales de creación sistemática de sentido, de significado social compartido por parte de la ciudadanía, a través de la interpretación del discurso informativo. Sin embargo, hasta el momento, este potente proceso de mediación simbólica sigue demandando una mayor profundidad teórica en la explicación de sus mecanismos cognitivos, y sobre todo, de sus vínculos específicos con la actividad mediática profesional.

En concreto, dentro de la generalidad del proceso social planteado, el profesor Casero Ripollés selecciona como objeto de estudio un fenómeno especialmente relevante, las crisis políticas. La orientación de tipo de objeto, entendido como casos significativos de ruptura del orden sociopolítico dado en un determinado contexto, sitúa el texto dentro del debate actual sobre comunicación política. Así, el presente trabajo tiene como objetivo general elaborar un modelo interpretativo sobre la acción ejercida por

\footnotetext{
* Departamento de Ciência da Comunicação da Universidade Jaume I Castellón, Espanha.
} 
los medios en la construcción de la realidad política derivada de procesos conflictivos o atípicos.

Más allá de la importancia y actualidad del objeto de estudio, uno de los principales puntos de interés del texto reside en su planteamiento y cumplido desarrollo como trabajo científico completo. Es necesario destacar la canónica estructura del libro dividido en cinco grandes bloques: desde un marco teórico general y especifico sobre la construcción mediática de la realidad, hasta la propuesta teórica novedosa del caso crítico, pasando por una doble aplicación empírica significativa.

En los tres primeros bloques se desglosa de forma progresiva el marco teórico de la investigación. En el primero (1), se define la sociología de la comunicación política italiana como vía de estudio principal. En concreto, de entrada se revisan sus dos principales antecedentes: la aportación de autores clásicos de la sociofenomenología como Alfred Schutz, o Peter Berger y Thomas Luckmann, y del funcionalismo sistémico como Nicklas Luhmann. Y a continuación, se profundiza en su base teórica específica, repasando sus principales autores, características y ámbitos de interés, tomando la obra de Giorgio Grossi como principal referencia. En el segundo bloque (2), se profundiza en las implicaciones de la información periodística en el proceso de construcción social de la realidad, especialmente en las características y contexto de la mediación simbólica realizada por los medios. Por último, el marco teórico se cierra con un tercer bloque (3) que pone el foco de atención en un aspecto concreto de la comunicación política: el análisis de los nexos entre información periodística y atipicidad. A partir del concepto de atipicidad de Schutz, y de la proyección mediática que plantea Grossi, el autor contextualiza la crisis política como un proceso político-mediático especialmente adecuado y relevante para el desarrollo de este estudio.

Tras una breve explicación del modelo metodológico a aplicar en el estudio del discurso informativo, en el cuarto bloque (4) se analizan empíricamente la construcción mediática de dos crisis políticas que afectaron al partido socialista en España durante la última década: la crisis en el PSE-EE (entre 2001-2002) y del PSPV-PSOE ( en 1999), tras la dimisión de sus respectivos secretarios generales (Nicolás Redondo Terreros y Joan Romero). En concreto, se revisa 
una muestra representativa, casi 350 unidades informativas, de la cobertura desarrollada por cuatro medios impresos españoles: dos periódicos estatales (El Pais y El Mundo), junto a las principales cabeceras del País Vasco y la Comunidad Valenciana en cada caso (El Correo Español-El Pueblo Vasco y Deia; Levante-El Mercantil Valenciano y Las Provincias).

Respecto a este bloque empírico, destaca la precisión metodológica del autor a la hora de articular la construcción mediática de las crisis en torno a una serie concreta de categorías de análisis: contexto comunicativo y político, volumen de oferta comunicativa, evolución cronológica, visibilidad temática, sistema de fuentes informativas, y grado de protagonismo y modalidad de relación entre los actores implicados (autorreferencialidad, personalización, espectacularización de la política, etc.)

A partir de las regularidades detectadas en los dos casos analizados, finalmente en el quinto bloque (5), como conclusión de la investigación, se define un modelo interpretativo, denominado "caso crítico", que trata de explicar cómo se construye informativamente la realidad política derivada de la crisis política. Este patrón interpretativo del "caso crítico", que se sitúa entre la generalidad del "caso excepcional" y la concreción del hecho-ruptura informativo planteados por Giorgio Grossi, representa otro de los puntos de interés del libro, ya que consigue sintetizar de forma clara y efectiva nueve características generalizables sobre la representación mediática de las crisis políticas (p.320).

En resumen, este libro representa una necesaria profundización teórica en el estudio de un concepto tan sugerente como es la construcción mediática de la realidad social. El avance de este texto se materializa en una doble aportación a los estudios de comunicación política en el contexto académico español y latinoamericano.

Por una parte, destacar el alto grado de novedad del marco teórico propuesto. La coherente combinación teórica entre la base sociofenomenológica de Schutz y la sociología de la comunicación política italiana, adquiere en el texto de Casero un correcta, completa y explícita conexión para el estudio de la información periodística como instrumento fundamental de construcción de la realidad social de la que carecía hasta el momento. 
Y por otra parte, subrayar la novedosa aplicación empírica, eligiendo la crisis política como un caso de estudio actual y relevante. Hasta ahora, autores como Schutz o Grossi solo habían tenido escasas aplicaciones parciales y de tipo teórico en nuestro contexto investigador. Este texto demuestra su potencial empírico y abre una interesante línea de investigación a confirmar en el futuro.

Sin duda, La construcción mediática de las crisis politicas ofrece un salto teórico cualitativo en el campo de la Comunicación política, y las aportaciones novedosas señaladas lo hacen muy recomendable para docentes e investigadores de esta especialidad y de teoría de la comunicación. 